\title{
Technical note: Extrapolation of hepatic glycogen concentration of the whole organ by performing a liver biopsy
}

\author{
M. Duplessis, ${ }^{1 *}$ ৫) L. Blais, ${ }^{2}$ W. Poisson, ${ }^{3}$ and C. L. Girard ${ }^{1}$ \\ ${ }^{1}$ Agriculture et Agroalimentaire Canada, Centre de recherche et développement de Sherbrooke, Sherbrooke, QC, J1M 0C8, Canada \\ ${ }^{2}$ Département de microbiologie et d'infectiologie, Université de Sherbrooke, Sherbrooke, QC, J1K 2R1, Canada \\ ${ }^{3}$ Département des sciences animales, Université Laval, Québec, QC, G1V 0A6, Canada
}

\begin{abstract}
Glycogen, a complex polysaccharide, is the form of storage of glucose in mammals that can be released rapidly when needed. Recent studies have mainly reported hepatic glycogen concentration for earlylactating cows, when the energy demand is higher than the energy supply from dry matter intake, driving the cow to use the energy stored as hepatic glycogen. Generally, liver samples are obtained through percutaneous needle biopsies in the right lobe of the liver. Our objective was to analyze the variation of glycogen concentration in the livers of Holstein and Jersey cows among different liver locations representing all lobes, to evaluate whether samples obtained by liver biopsies are representative of the whole organ. Liver from 10 culled lactating cows (5 Holstein and 5 Jersey cows) from 30 to 113 mo of age at slaughter were obtained. Each liver was sampled no more than $3 \mathrm{~h}$ after death on the following sites: 3 sites in the right lobe ( 1 to 3 ), 2 in the diaphragmatic surface of the left lobe (4 and 5), 3 in the visceral surface of the left lobe (6 to 8), 1 in the quadrate lobe (9), and 1 in the caudate lobe (10). Samples were snap frozen in liquid $\mathrm{N}_{2}$ and were then analyzed for glucose concentration after conversion of glycogen to glucose using amyloglucosidase (EC 3.2.1.3). Glycogen results are reported as grams of glucose per $100 \mathrm{~g}$ of wet weight of liver (i.e., percent of wet weight of liver). Liver weights averaged 5.1 [standard deviation (SD) 1.2, minimum 3.3, maximum 6.2] $\mathrm{kg}$ for Holstein and 6.0 (SD 1.8, minimum 4.7, maximum 8.9) $\mathrm{kg}$ for Jersey cows. Holstein cows [1.31, standard error of the mean (SEM) $0.05 \%$ of wet weight] had greater liver glycogen concentration than did Jersey cows $(0.75$, SEM $0.05 \%$ of wet weight). No significant difference was noted among the 10 liver locations regarding glycogen concentration and averaged, for both breeds, $1.03 \%$
\end{abstract}

Received November 13, 2019.

Accepted January 6, 2020.

*Corresponding author: melissa.duplessis@canada.ca of wet weight (SEM 0.10). These results suggest that, in dairy cows, percutaneous needle liver biopsy in the right lobe is an accurate technique to fairly extrapolate glycogen concentration of the whole organ.

Key words: glycogenolysis, cattle, glycogen, liver

\section{Technical Note}

Glycogen is a complex polysaccharide that is stored in the liver and skeletal muscles of animals and can be rapidly mobilized to provide glucose (Moran et al., 2012). At the onset of lactation in dairy cows, energy requirements for milk production are greater than the energy supply obtained by feed intake, resulting in a transient negative energy balance (Drackley, 1999). During this period, liver glycogen stores are used as a source of energy (De Koster and Opsomer, 2013). Indeed, it has been repeatedly shown that liver glycogen concentration drastically decreases in early lactation (Weber et al., 2013, 2015; McCarthy et al., 2015), suggesting glycogenolysis. Recent manuscripts reporting hepatic concentrations of glycogen have aimed to evaluate the effects of different treatments or physiological conditions on liver glucose metabolism during the transition period and in early lactation (Hammon et al., 2009; Mann et al., 2018; Zenobi et al., 2018). Percutaneous needle liver biopsy was used in those studies, as it is the easiest way to obtain liver samples from live animals. Liver position changes according to the physiological state of the animal, as during gestation (Skaar and Grummer, 1989); nevertheless, the right lobe is always sampled when performing a biopsy (Gerspach et al., 2017). Liver sampling with this technique typically represents less than $0.1 \%$ of the whole liver and relies on the assumption that glycogen concentration among liver lobes is homogeneous. However, Matsubara et al. (1982) showed that several hepatic enzymes were not homogeneously distributed within the liver lobes of rats, suggesting different enzymatic activity among lobes that could modify metabolite concentrations. However, it is not known whether, in cows, hepatic 
glycogen concentration varies within liver localizations and whether, consequently, liver biopsy samples can be considered representative of the whole organ. Thus, this experiment was undertaken to assess the variation of hepatic glycogen concentration among different liver locations in Holstein and Jersey cows. This analysis allowed evaluation of whether hepatic glycogen concentration measured from samples obtained via percutaneous liver biopsies can be representative of the whole liver.

Livers from 10 culled and lactating cows (5 Holstein and 5 Jersey cows) were sampled. To be included in this study, it was required that cows were not culled for a liver disease. Only livers displaying no visual abscesses or damage were used in this study. Age at culling varied from 30 to 113 mo for both breeds. Cows were stunned and exsanguinated in a commercial slaughterhouse. After slaughter, the liver was immediately removed from the body, weighed, and stored at $4^{\circ} \mathrm{C}$ until sampling, with the latter performed within $3 \mathrm{~h}$ after death. Ten different liver locations were studied, according to Gerspach et al. (2017): 3 sites in the right lobe, 2 in the diaphragmatic surface of the left lobe, 3 in the visceral surface of the left lobe, 1 in the quadrate lobe, and 1 in the caudate lobe (Figure 1). Each site was sampled in approximately the same place for each liver. After sampling, liver tissues were snap frozen with liquid $\mathrm{N}_{2}$, put on dry ice for transportation, and thereafter stored at $-80^{\circ} \mathrm{C}$ until analysis.

Liver tissue was analyzed for glycogen concentration as per Bernal-Santos et al. (2003), with modifications. Approximately $200 \mathrm{mg}$ of tissue was weighed, homog- enized with $2.4 \mathrm{~mL}$ of $30 \% \mathrm{KOH}$ using a glass tissue homogenizer (Eberbach, Belleville, MI), and kept on ice. For each site, 2 separate samples of $200 \mathrm{mg}$ of liver tissue each were created. Samples were then placed in a boiling water bath for 20 min and cooled at room temperature before $2.8 \mathrm{~mL}$ of $60 \%$ ethanol was added to the mixture, vortexed to break the pellet down and homogenize, and centrifuged at $2,000 \times g$ and $4^{\circ} \mathrm{C}$ for $20 \mathrm{~min}$, after which supernatant was discarded. The last 4 steps (i.e., addition of ethanol, vortexing, centrifugation, and discarding of supernatant) were repeated 2 more times, but 10 and $5 \mathrm{~mL}$ of $60 \%$ ethanol were respectively added during the first and second repetitions. Then, $8 \mathrm{~mL}$ of $0.2 \mathrm{~N}$ acetate buffer ( $\mathrm{pH} 4.5$ ) was added to the pellet, the mixture was vortexed to homogenize, and $200 \mu \mathrm{L}$ was pipetted into 2-mL Eppendorf tubes. Ten microliters of antipain (EMD Millipore Corp., Billerica, MA), a protease inhibitor, followed by $30 \mu \mathrm{L}$ of an enzyme solution of amyloglucosidase (4.07 units; from Aspergillus niger, Sigma A-1602; EC 3.2.1.3; Sigma-Aldrich, Oakville, ON, Canada) were added. The solution was vortexed to homogenize and incubated at $55^{\circ} \mathrm{C}$ for 60 min to convert liver glycogen to glucose. The glucose concentrations of samples were then analyzed using a commercial kit [Glucose (Trinder) Assay, Sekisui Diagnostics, Charlottetown, PEI, Canada]. Results obtained were expressed as micrograms of glucose per gram of wet weight of liver and are presented as percent of wet weight of liver. All samples were analyzed in triplicate, and the inter-assay CV was $10.3 \%$. The intra-assay CV between triplicates was $3.8 \%$ and was $4.9 \%$ between samples of the same liver site.

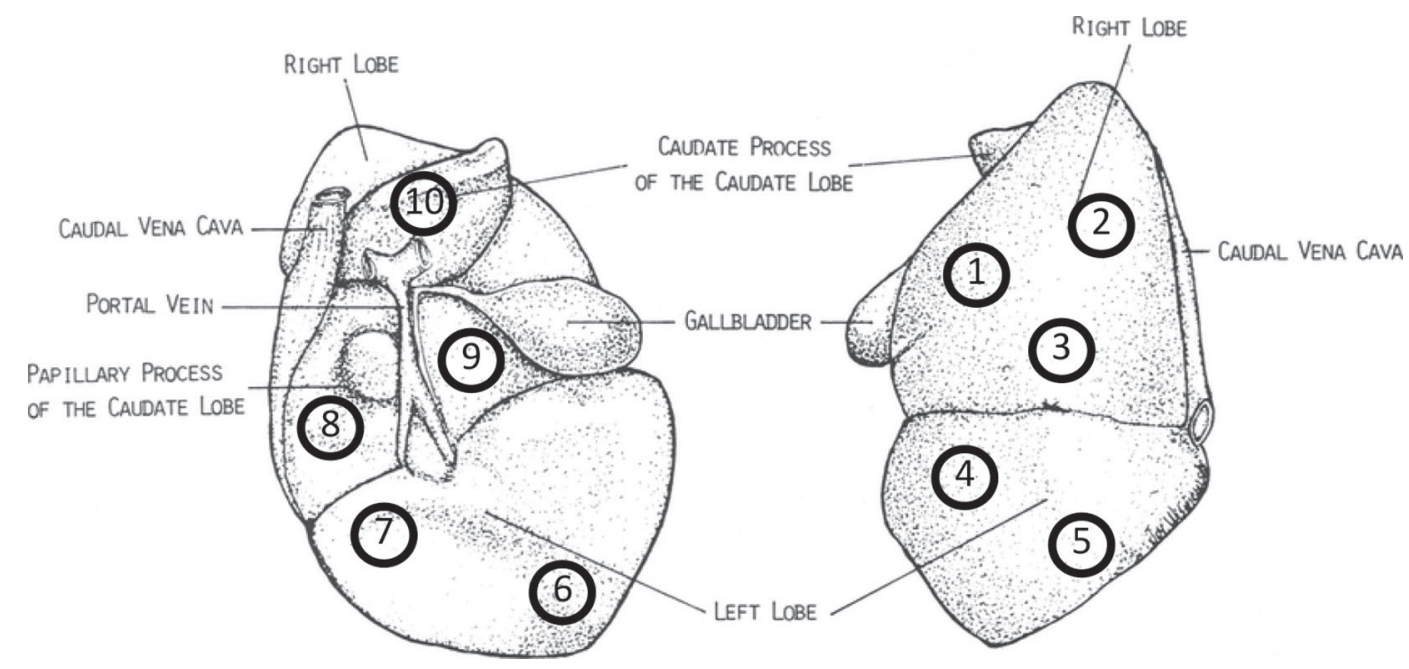

Figure 1. Liver sampling sites: right lobe (1-3); left lobe, diaphragmatic surface (4, 5); left lobe, visceral surface (6-8); quadrate lobe (9); caudate lobe (10; locations from Gerspach et al., 2017). The liver drawing was adapted from Wisniewski et al. (1987) by permission of Oxford University Press and the American Society of Animal Science (Champaign, IL). 
The quantity of glycogen in the liver was computed by multiplying hepatic glycogen concentration by liver weight. Age at culling was categorized as followed: (1) 36 mo or less (2 Holstein and 2 Jersey); (2) between 36 and 84 mo (2 Holstein and 2 Jersey); and (3) 84 mo or greater (1 Holstein and 1 Jersey). Proc MEANS of SAS (SAS Institute, 2012) was used to compute descriptive statistics. Linear mixed model was assessed using the MIXED procedure of SAS with liver site, breed, liver site $\times$ breed interaction, and age at culling categories as fixed effects. Liver sites were defined as the 10 locations described above. Liver weight was included in the model as a covariate $(P=0.05$; Kaps and Lamberson, 2017). Quantity of glycogen in the liver was also evaluated using the MIXED procedure of SAS, with the same fixed effects described except that no covariate was used. Normality and homoscedasticity were visually evaluated with residuals. A Tukey's honest significant difference test was performed when results from categorical variables reached significance. The relationship between age at culling and liver weight was assessed using Proc CORR of SAS. Results were considered significant when $P \leq 0.05$.

Liver weights averaged 5.1 (SD 1.2, minimum 3.3, maximum 6.2) $\mathrm{kg}$ for Holstein and 6.0 (SD 1.8, minimum 4.7, maximum 8.9) $\mathrm{kg}$ for Jersey cows. For an unknown reason, it appears that livers from Holstein cows in the current study were smaller than reported values in the literature (Gibb et al., 1992; Baldwin et al., 2004). Average ages at culling per category were: (1) 31.8 (SD 2.1, minimum 30, maximum 35) mo; (2) 63.5 (SD 13.8, minimum 49, maximum 82) mo; and (3) 112.5 (SD 0.5, minimum 112, maximum 113) mo. Age at culling and liver weight were not well correlated (Pearson $\mathrm{r}=0.42, P=0.23$ ).

Liver glycogen concentrations were greater for Holstein than for Jersey cows $(P<0.0001$; Table 1$)$. Hepatic glycogen concentrations of Holstein cows were similar to or above previously reported values for cows in early lactation (McCarthy et al., 2015; Mann et al., 2018). To the best of our knowledge, this study is the first one reporting hepatic glycogen concentration of Jersey cows. Hepatic glycogen concentrations varied according to age at culling $(P<0.0001)$. The lowest glycogen concentrations were obtained for the oldest group (Table 1). Moreover, cows between 36 and 84 mo at time of slaughter had the greatest hepatic glycogen concentrations. One limitation of this study is that DIM of cows at culling could not be determined, as it was not possible to access personal cow file data. Because it has been shown that hepatic glycogen concentration varies according to lactation stage (Weber et al., 2013) and few cows per category of age at culling were in- volved, it cannot be ruled out that the effect of the stage of lactation was confounded by the effect of age at culling. We did not observe any difference between liver locations on glycogen concentration $(P=0.89$; Table 1 ), and concentrations averaged $1.03 \pm 0.10 \%$ of tissue wet weight for all cows. Another analysis was carried out to evaluate hepatic glycogen concentration among liver lobes instead of liver locations. It was considered that the cow liver has 4 lobes: right, left, quadrate, and caudate. We found no difference among liver lobes on glycogen concentration $(P=0.83)$. Indeed, regardless of breed, hepatic glycogen concentration averaged 0.97 , $1.08,0.98$, and $0.98 \pm 0.10$ for right, left, quadrate, and caudate lobes, respectively. Hu et al. (2017) concluded that glycogen molecular weight distribution of different rat liver lobes was similar. We found that glycogen quantity in the liver was greater for Holstein $(68.6 \pm$ $3.8 \mathrm{~g})$ than for Jersey cows $(46.1 \pm 3.8 \mathrm{~g} ; P<0.0001)$. Table 2 shows liver weight and descriptive statistics regarding hepatic glycogen concentration among cows. It can be observed from this table that the difference between the highest and the lowest hepatic glycogen concentrations among liver locations varied from 0.28 to $1.03 \%$ of wet weight among cows.

Our results suggest that liver biopsies are representative of the whole liver regarding glycogen concentration in dairy cows. Although some variations exist among

Table 1. Hepatic glycogen concentration (\% of wet weight) according to breed, age at culling, and liver sampling locations

\begin{tabular}{lccc}
\hline Item & Glycogen $^{1}$ & SEM & $P$-value \\
\hline Breed & & & $<0.0001$ \\
$\quad$ Holstein & 1.31 & 0.05 & \\
$\quad$ Jersey & 0.75 & 0.05 & $<0.0001$ \\
Age at culling (mo) & $1.18^{\mathrm{b}}$ & 0.05 & \\
$\leq 36$ & $1.43^{\mathrm{a}}$ & 0.05 & \\
36 to 84 & $0.49^{\mathrm{c}}$ & 0.09 & \\
$\geq 84$ & & & 0.89 \\
Liver locations & 0.99 & 0.10 & \\
Right lobe 1 & 0.92 & 0.10 & \\
Right lobe 2 & 1.01 & 0.10 & \\
Right lobe 3 & 1.04 & 0.10 & \\
Left lobe (diaphragmatic) 4 & 1.16 & 0.10 & \\
Left lobe (diaphragmatic) 5 & 1.09 & 0.10 & \\
Left lobe (visceral) 6 & 1.09 & 0.10 & \\
Left lobe (visceral) 7 & 1.05 & 0.10 & \\
Left lobe (visceral) 8 & 0.98 & 0.10 & \\
Quadrate lobe 9 & 0.99 & 0.10 & \\
Caudate lobe 10 & & \\
\hline
\end{tabular}

${ }^{\mathrm{ac}}$ Different superscripts within a column indicate significant differences $(P<0.003)$.

${ }^{1}$ Obtained from the conversion of glycogen to glucose using the enzyme amyloglucosidase and presented as grams of glucose per $100 \mathrm{~g}$ of wet weight of liver (i.e., $\%$ of wet weight).

${ }^{2}$ Liver site $\times$ breed interaction, $P=0.96$.

${ }^{3}$ Adapted from Gerspach et al. (2017). 
Table 2. Liver weight $(\mathrm{kg})$ and average, SD, minimum, and maximum hepatic glycogen concentration (\% of wet weight $)^{1}$ among liver locations of the 10 cows studied

\begin{tabular}{lccccc}
\hline & & \multicolumn{4}{c}{ Hepatic glycogen concentration } \\
\cline { 3 - 5 } Cow & Liver weight & Average & SD & Minimum & Maximum \\
\hline Holstein & & & & & \\
1 & 6.2 & 1.98 & 1.21 & 1.84 & 2.18 \\
2 & 5.8 & 1.49 & 1.01 & 1.34 & 1.62 \\
3 & 3.3 & 1.26 & 1.50 & 1.05 & 0.80 \\
4 & 5.5 & 0.62 & 0.16 & 0.23 & 2.27 \\
5 & 4.6 & 1.62 & 0.34 & 1.24 & 0.65 \\
Jersey & & & & & 0.37 \\
6 & 8.9 & 0.55 & 0.10 & 1.04 & 0.76 \\
7 & 4.7 & 1.33 & 0.24 & 0.34 & 1.33 \\
8 & 6.8 & 0.53 & 0.14 & 0.83 & 1.48 \\
9 & 5.1 & 0.99 & 0.14 & 0.58 & \\
10 & 4.7 & 1.03 & 0.31 &
\end{tabular}

${ }^{1}$ Obtained from the conversion of glycogen to glucose by the enzyme amyloglucosidase and presented as grams of glucose per $100 \mathrm{~g}$ of wet weight of liver (i.e., \% of wet weight).

liver locations, these variations are not related to the sampling site. Hence, even though only the right lobe is sampled when performing liver biopsies, this sampling technique can be used to extrapolate glycogen concentration of all hepatic lobes. It should be kept in mind, however, that some physiological differences (e.g., remaining blood, tissue metabolism) might exist between liver samples collected from live or dead animals.

\section{ACKNOWLEDGMENTS}

We are grateful to Katy Paquet and Abattoir Transbec (Manseau, QC, Canada) for providing livers and for kindly allowing us to sample livers at their slaughterhouse. We thank Liette Veilleux, Véronique Roy, and Valérie Beaudet (Agriculture et Agroalimentaire Canada, Sherbrooke, QC, Canada) for technical help. We thank Maris McCarthy (formerly at Cornell University, Ithaca, NY, now at Micronutrients, Indianapolis, IN) for providing the glycogen protocol. The present project was a publicly supported research within Agriculture and Agri-Food Canada (grant number 1614; AAFC, Ottawa, ON, Canada). The authors have not stated any conflicts of interest.

\section{REFERENCES}

Baldwin, R. L. V., K. R. McLeod, and A. V. Capuco. 2004. Visceral tissue growth and proliferation during the bovine lactation cycle. J. Dairy Sci. 87:2977-2986. https://doi.org/10.3168/jds.S0022 -0302(04)73429-3.

Bernal-Santos, G., J. W. Perfield II, D. M. Barbano, D. E. Bauman, and T. R. Overton. 2003. Production responses of dairy cows to dietary supplementation with conjugated linoleic acid (CLA) during the transition period and early lactation. J. Dairy Sci. 86:32183228. https://doi.org/10.3168/jds.S0022-0302(03)73925-3.
De Koster, J. D., and G. Opsomer. 2013. Insulin resistance in dairy cows. Vet. Clin. North Am. Food Anim. Pract. 29:299-322. https: //doi.org/10.1016/j.cvfa.2013.04.002.

Drackley, J. K. 1999. Biology of dairy cows during the transition period: The final frontier? J. Dairy Sci. 82:2259-2273. https://doi .org/10.3168/jds.S0022-0302(99)75474-3.

Gerspach, C., S. Imhasly, R. Klingler, M. Hilbe, S. Hartnack, and M. Ruetten. 2017. Variation in fat content between liver lobes and comparison with histopathological scores in dairy cows with fatty liver. BMC Vet. Res. 13:98. https://doi.org/10.1186/s12917-017 -1004-9.

Gibb, M. J., W. E. Ivings, M. S. Dhanoa, and J. D. Sutton. 1992. Changes in body components of autumn-calving Holstein-Friesian cows over the first 29 weeks of lactation. Anim. Prod. 55:339-360. https://doi.org/10.1017/S0003356100021036.

Hammon, H. M., G. Stürmer, F. Schneider, A. Tuchscherer, H. Blum, T. Engelhard, A. Genzel, R. Staufenbiel, and W. Kanitz. 2009. Performance and metabolic and endocrine changes with emphasis on glucose metabolism in high-yielding dairy cows with high and low fat content in liver after calving. J. Dairy Sci. 92:1554-1566. https://doi.org/10.3168/jds.2008-1634.

Hu, Z., X. Tan, B. Deng, H. Gan, X. Jiang, K. Wang, C. Li, E. Li, R. G. Gilbert, and M. A. Sullivan. 2017. Implications for biological function of lobe dependence of the molecular structure of liver glycogen. Eur. Polym. J. 90:105-113. https://doi.org/10.1016/j .eurpolymj.2017.03.009.

Kaps, M., and W. R. Lamberson. 2017. Biostatistics for Animal Science. 3rd ed. CAB International, London, UK.

Mann, S., F. A. Leal Yepes, J. J. Wakshlag, E. Behling-Kelly, and J. A. A. McArt. 2018. The effect of different treatments for earlylactation hyperketonemia on liver triglycerides, glycogen, and expression of key metabolic enzymes in dairy cattle. J. Dairy Sci. 101:1626-1637. https://doi.org/10.3168/jds.2017-13360.

Matsubara, T., A. Touchi, and A. Ogawa. 1982. Heterogeneous distribution of the cytochrome P-450 monooxygenase system in rat liver lobes. Jpn. J. Pharmacol. 32:999-1011. https://doi.org/10.1254/ jjp.32.999.

McCarthy, M. M., M. S. Piepenbrink, and T. R. Overton. 2015. Associations between hepatic metabolism of propionate and palmitate in liver slices from transition dairy cows. J. Dairy Sci. 98:70157024. https://doi.org/10.3168/jds.2015-9695.

Moran, L. A., H. R. Horton, G. K. Scrimgeour, and M. D. Perry. 2012. Principles of Biochemistry. 5th ed. Pearson Education Inc., Glenview, IL.

SAS Institute. 2012. User's Guide: Statistics. Version 9.4. SAS Institute, Cary, NC. 
Skaar, T. C., and R. R. Grummer. 1989. Distribution of lipid in hepatic tissue of dairy goats in positive and negative energy balance. Zentralbl Veterinarmed A 36:555-558. https://doi.org/10.1111/j .1439-0442.1989.tb00765.x.

Weber, C., C. Hametner, A. Tuchscherer, B. Losand, E. Kanitz, W. Otten, S. P. Singh, R. M. Bruckmaier, F. Becker, W. Kanitz, and H. M. Hammon. 2013. Variation in fat mobilization during early lactation differently affects feed intake, body condition, and lipid and glucose metabolism in high-yielding dairy cows. J. Dairy Sci. 96:165-180. https://doi.org/10.3168/jds.2012-5574.

Weber, C., B. Losand, A. Tuchscherer, F. Rehbock, E. Blum, W. Yang, R. M. Bruckmaier, P. Sanftleben, and H. M. Hammon. 2015. Effects of dry period length on milk production, body condition, metabolites, and hepatic glucose metabolism in dairy cows. J. Dairy Sci. 98:1772-1785. https://doi.org/10.3168/jds.2014-8598.
Wisniewski, J. A., D. E. Moody, B. D. Hammock, and L. R. Shull. 1987. Interlobular distribution of hepatic xenobiotic-metabolizing enzyme activities in cattle, goats and sheep. J. Anim. Sci. 64:210215. https://doi.org/10.2527/jas1987.641210x.

Zenobi, M. G., T. L. Scheffler, J. E. Zuniga, M. B. Poindexter, S. R. Campagna, H. F. Castro Gonzalez, A. T. Farmer, B. A. Barton, J. E. P. Santos, and C. R. Staples. 2018. Feeding increasing amounts of ruminally protected choline decreased fatty liver in nonlactating, pregnant Holstein cows in negative energy status. J. Dairy Sci. 101:5902-5923. https://doi.org/10.3168/jds.2017-13973.

\section{ORCIDS}

M. Duplessis @ (ㄴ) https://orcid.org/0000-0003-3503-6612 